\title{
Paraproteinaemia in neurological disease: incidence, associations, and classification of monoclonal immunoglobulins
}

\author{
SIDNEY N KAHN,* PAMELA G RICHES, $\dagger$ AND J KOHN! \\ From the *Department of Chemical Pathology, The National Hospital, Queen Square, London WC1N 3BG, \\ $\dagger$ Specific Protein Reference Unit, Westminster Hospital, London SWIP 2AR, $\ddagger$ Biochemistry Department, \\ University of Surrey, Guildford, and $\ddagger$ Royal Marsden Hospital, Sutton, Surrey, UK
}

SUMMARY Fifty-six patients presenting with neurological complaints were found to have paraproteinaemia unassociated with immunocytic malignancy; 16 patients presented with peripheral neuropathy. There was an association between IgM paraproteinaemia and an idiopathic neuropathy with markedly slowed nerve conduction velocities.

Disturbances in neurological function associated with paraproteinaemic states are well documented, especially in patients suffering from myeloma or Waldenström's macroglobulinaemia. ${ }^{1-6}$ In recent years, increasing attention has been given to paraproteinaemia in the absence of evidence of immunocytic malignancy, the so-called 'benign (idiopathic) monoclonal gammopathies'. ${ }^{7-17}$ The occurrence of neurological disturbances associated with benign paraproteinaemias is much less common than in myeloma and Waldenström's macroglobulinaemia, $71011131517-24$ and there have been only two reports on the occurrence of paraproteinaemia in patients presenting with neurological disorders. ${ }^{21} 25$

We have investigated a group of patients referred to a specialist neurological centre who were found on routine clinical laboratory testing to have paraproteinaemia.

\section{Patients and methods}

The clinical material consisted of patients of the National Hospitals for Nervous Diseases at Queen Square and Maida Vale in whose serum a paraprotein was detected on routine serum protein electrophoresis in agarose, performed as part of a liver function test profile. The period of study was from July 1975 to December 1978. Routine laboratory investigations were carried out in the clinical pathology laboratories at the National Hospital, Queen Square; additional investigations of para-

Received for publication 22 November 1979 proteinaemia followed the scheme suggested by Kohn. ${ }^{26}$ As it is a specialist referral centre, a number of the National Hospital's patients is drawn from remote areas and other countries, thus it was not always possible for patients to re-attend for investigation. In some of these cases, follow-up samples of serum and urine were received from other hospitals in the United Kingdom. When possible, follow-up tests were done initially after six months and then annually.

Paraprotein typing was carried out either by immunoelectrophoresis in agar gel or latterly by immunofixation electrophoresis on cellulose acetate membrane. ${ }^{27}$ Paraprotein concentration was measured by densitometry of Ponceau-S stained cellulose acetate electrophoretograms. Bence-Jones protein, if present, was detected by electrophoresis on cellulose acetate of unconcentrated and concentrated urine and confirmed immunochemically. Serum immunoglobulin levels of classes other than the paraprotein were measured by automated immunoprecipitation.

During the period of study, electrophoresis was carried out on approximately 14000 sera. Fiftyeight cases of paraproteinaemia were detected which did not fulfil recognised criteria for the diagnosis of multiple myeloma or Waldenström's macroglobulinaemia at the time of presentation, ${ }^{12} 2628$ giving an incidence of this type of paraproteinaemia in the population studied of approximately $0.4 \%$. Two of these patients were subsequently found to have solitary plasmacytomas. A further 10 patients with paraproteinaemia presented with an established diagnosis of myeloma or Waldenström's macroglo617 
bulinaemia. These 12 patients will not be considered further.

The modes of presentation of the remaining 56 patients without evidence of immunocytoma, here designated as 'benign' paraproteinaemia, are listed in Table 1. The 16 patients with neuropathies fell into two groups: group 1 consisted of nine patients with idiopathic peripheral neuropathy and very slow nerve conduction velocities; group 2 comprised seven patients with less uniform electrophysiological findings and other conditions known to be associated with peripheral neuropathy. Detailed studies of these patients will be presented elsewhere (Smith, Eames and Kahn, unpublished).

Table 1 Clinical presentation of patients with 'benign' paraproteinaemia

\begin{tabular}{lll}
\hline & $\begin{array}{l}\text { Number of patients } \\
(n=56)\end{array}$ \\
\hline $\begin{array}{l}\text { Peripheral neuropathy } \\
\text { Demyelinating }\end{array}$ & 16 \\
$\begin{array}{l}\text { Other } \\
\text { Space-occupying lesions }\end{array}$ & 9 & \\
$\quad$ Glioma & 1 & 6 \\
$\quad$ Meningioma & 1 & \\
$\quad$ Haemangioblastoma & 1 & \\
Neurofibroma & 1 & \\
$\quad$ Pituitary & 1 & \\
$\quad$ Metastatic & 1 & 4 \\
Cervical spondylosis & & \\
Dementia & & 4 \\
Motor neurone disease & & 2 \\
Cerebrovascular accident & & 2 \\
Multiple sclerosis & & 18 \\
Miscellaneous & & \\
\hline
\end{tabular}

A third group of $\mathbf{4 0}$ patients presented with a variety of neurological symptoms or signs (group 3 ).

There was no evidence to suggest an unusual distribution of paraproteins with respect to age or sex.

A history of malignant disease was obtained in four patients from group 3. All of these were female and had been treated for breast carcinoma nine months, 10 years, 13 years, and 23 years before neurological presentation. None had any evidence of recurrence.

Ten patients died, five during or shortly after initial hospitalisation. Postmortem examination was performed in only four patients and revealed no evidence of immunocytic dyscrasia.

Thirty-two patients were followed for more than 12 months (range 14-48, mean 28.4 , months). The paraprotein concentration rose significantly in one patient, otherwise well, over a 22-month period. There were no significant changes in laboratory results in any of the remaining 24 patients, except that in three cases the paraprotein appeared to be transient.

\section{Results}

CLINICAL LABORATORY INVESTIGATIONS

No relevant abnormalities were found on routine clinical laboratory investigations.

Twenty-six sternal bone marrows were examined, of which 17 were entirely normal. Four patients with neuropathy had relative increases in lymphocytes ranging from 15 to $26 \%$ of total nucleated cells. One patient in group 1 with $20 \%$ marrow plasmacytosis and tetrameric Bence-Jones proteinaemia without evidence of malignancy to date is the subject of a separate report (Kahn, Riches, and Turner, unpublished). Five patients in group 3 had relative increases in bone marrow lymphocytes ranging from 20 to $45 \%$ of total nucleated cells. The bone marrow histology was not thought to be typical of immunocytic dyscrasia in any patient.

Full skeletal survey was performed in 23 patients and partial surveys in a further 10. Eight patients had chest and skull films only, two chest only, two skull only, and one spine only. Ten patients had no $x$-ray studies. None of the films suggested the presence of myelomatous deposits.

\section{PARAPROTEIN STUDIES}

The paraprotein concentration reached $15 \mathrm{~g} / 1$ in only one patient with neuropathy. Two patients in group 3 had IgG kappa paraproteins of 35 and 37 $\mathrm{g} / \mathrm{l}$. Both had normal skeletal surveys, and one a normal bone marrow but a trace of monoclonal free light chains in the urine. The other had a bone marrow containing $20 \%$ lymphocytes and $6 \%$ plasma cells but no free light chains in the urine.

Levels of polyclonal immunoglobulins were normal except in two patients with marginally decreased IgG. In addition, a further 11 patients had marginally low levels of IgA or IgM, which were not considered significantly abnormal.

Traces of free light chains $(<0 \cdot 2 \mathrm{~g} / \mathrm{l})$ were consistently present in the urine of six patients.

The immunoglobulin class distribution of the paraproteins is correlated with the three diagnostic categories in Table 2 . There is a significantly higher incidence of IgM paraproteinaemias in group 1 compared with groups 2 and 3 (P $<0.01$, Fisher's exact test).

Multiband paraproteinaemia ${ }^{29}$ was detected in six patients (Table 2).

The overall distribution of light chain types gives a kappa: lambda ratio of 1.7 ; however, all the paraproteins were of kappa type in group 1.

\section{Discussion}

There has been only one report on the incidence of 
Table 2 Paraprotein class $\mathrm{v}$ clinical diagnosis

\begin{tabular}{lllll}
\hline & $\begin{array}{l}\text { Group I } \\
(n=9)\end{array}$ & $\begin{array}{l}\text { Group 2 } \\
(n=7)\end{array}$ & $\begin{array}{l}\text { Group 3 } \\
(n=40)\end{array}$ & $\begin{array}{l}\text { Total } \\
(n=56)\end{array}$ \\
\hline IgG & 2 & 2 & 27 & 31 \\
IgA & 0 & 2 & 0 & 2 \\
IgM & 7 & 2 & 9 & 18 \\
BJ & 1 & 0 & 0 & 1 \\
Multiband & $2^{*}$ & $1 \dagger$ & $4 \ddagger$ & 7 \\
NT & 0 & 1 & 5 & 6 \\
\hline
\end{tabular}

$* \operatorname{IgM}+\operatorname{IgM}=1$

$\mathbf{I g} M+\mathbf{I g G}=1$

†IgM + IgM

$\mp \operatorname{IgM}+\mathbf{I g M}=1$

IgM + IgG $=1$

IgG + IgG $=1$

BJ = light chain only

NT $=$ not tested

paraproteinaemia, malignant and benign, in patients presenting with neurological syndromes. ${ }^{21}$ The condition of benign paraproteinaemia, first described by Waldenström as 'essential hypergammaglobulinaemia,' differs from the malignant immunocytic dyscrasias in the absence of (1) widespread bone lesions, (2) significant anaemia, (3) significant Bence-Jones proteinuria, (4) bone marrow plasmacytosis or atypical lymphocytosis, (5) immunosuppression, and (6) progressive increase in the paraprotein concentration. ${ }^{28}$ In the absence of signs of overt malignancy, this last criterion is probably the most useful diagnostically ${ }^{12} 30$ since there appears to be no biochemical, immunological, or histochemical way of differentiating benign from malignant conditions. ${ }^{31}$ The occurrence of a malignant evolution at any stage cannot be ruled out. In the present study patients fulfilling the criteria listed above have been designated as 'benign', although prolonged follow-up may alter this classification.

Benign paraproteinaemia has been reported in healthy people and in patients suffering from a variety of diseases. Some authors have reported associations with non-reticular neoplasia, cardiovascular disease, infections (acute and chronic), gastrointestinal disease (including disorders of the biliary tract), and certain autoimmune disorders. ${ }^{\text {? }}$ 9-11 13-1517-1922 2332 In view of the age-related incidence of both benign and malignant paraproteinaemia, 81733 it is perhaps not surprising that some of the commoner 'associations' include cardiovascular disease and non-reticular neoplasms, and it is probable that in these cases there may be no connection between these conditions. Some of the other frequent associations (lymphoreticular neoplasia, autoimmune disorders, and infective states) may be relevant to the production of monoclonal immunoglobulins.

The overall incidence of benign paraproteinaemia in approximately $0.4 \%$ of our hospital population may reflect the age distribution within that population. However, there is an unusually high incidence of patients with peripheral neuropathy, which occurred in approximately $28 \%$ of those with paraproteinaemia. The frequency distribution of the paraprotein immunoglobulin classes listed in Table 2 shows that the overall incidence of IgM paraproteins is higher, and of $\operatorname{IgA}$ lower, than in most previously published series (Table 3 ). There is a still more marked disproportion of IgM paraproteins in those patients with the demyelinating type of peripheral neuropathy $(78 \%)$ compared with other types of neuropathy $(25 \%)$ and other neurological disorders $(19 \%)$. The distribution of light chain types did not reveal any imbalance when considered in relation to heavy chain class.

Matzke et $a .^{21}$ presented data on five patients with apparently 'benign' paraproteinaemia. One of these, described as a 'transitional form between Waldenström's macroglobulinaemia and chronic lymphocytic leukaemia', but without any evidence for this diagnosis, presented with an idiopathic peripheral neuropathy. Massey et al. ${ }^{37}$ and Swash et $a l .{ }^{38}$ have each described one case of peripheral neuropathy associated with IgM paraproteinaemia but without evidence of Waldenström's macroglobulinaemia. Recently, Dalakas and Engel ${ }^{25}$ have described 11 patients with 'benign' paraproteinaemia of IgG or IgM class who presented with peripheral neuropathies. They suggest that this may represent a distinct subgroup of neuropathies, possibly autoimmune.

In an electrophoretic study of serum proteins in 116 patients with neuropathies of different types, including 33 patients with idiopathic neuropathies, Nusselt et al $^{39}$ found no significant gamma-globulin abnormalities. This finding may suggest that the association between 'benign' paraproteinaemia and neuropathy is uncommon. An alternative explanation is that their use of agar gel as the electrophoretic medium may have failed to demonstrate the presence of small paraprotein bands, as Link ${ }^{40}$ has shown.

Indirect immunofluorescence testing has indicated the presence of high-titre monoclonal IgM kappa antibodies which bind to heterologous myelin in the sera of the group 1 patients with IgM paraproteinaemia. Direct immunofluorescence studies of biopsied peripheral nerve from some of the same patients have demonstrated monoclonal IgM kappa attached to myelin sheaths. These results will be presented elsewhere (Kahn, Lacey, and Whybrew, unpublished). In the light of the findings presented in this paper and the results of the immunofluorescent studies, we conclude that the association between a specific type of peripheral neuropathy 
Table 3 Immunoglobulin class distribution in benign paraproteinaemia

\begin{tabular}{|c|c|c|c|c|c|c|c|}
\hline Reference & $n$ & $\lg G$ & $\operatorname{Ig} A$ & $I g M$ & Light chain & Multiband & Untyped \\
\hline This study & 56 & $55.4 \%$ & $3.6 \%$ & $32 \cdot 1 \%$ & $1.8 \%$ & $12 \cdot 5 \%$ & $10.7 \%$ \\
\hline Abramson and Shattil ${ }^{7}$ & 34 & $47 \cdot 1$ & $11 \cdot 8$ & $26 \cdot 5$ & 0 & 0 & $17 \cdot 6^{10}$ \\
\hline Clauvel et al. ${ }^{10}$ & 54 & $75 \cdot 9$ & $12 \cdot 9$ & $5 \cdot 5$ & 0 & $5 \cdot 5$ & 0 \\
\hline$K_{\text {Yyle }}{ }^{13}$ & 241 & 75 & 10 & 15 & 0 & 2 & 0 \\
\hline Michaux and Heremans ${ }^{14}$ & 30 & 70 & 20 & $13 \cdot 3$ & 0 & $3 \cdot 3$ & 0 \\
\hline Pick et al. ${ }^{15}$ & 100 & 86 & 14 & 0 & 0 & 9 & $\mathbf{0}$ \\
\hline Ameis et al..$^{18}$ & 301 & $72 \cdot 5$ & $12 \cdot 4$ & 6.4 & 0 & $1 \cdot 3$ & 5 \\
\hline Peltonen et al..$^{22}$ & 89 & $77 \cdot 5$ & $13 \cdot 5$ & 9 & 0 & 0 & 0 \\
\hline Lindstrom and Dahlström ${ }^{31}$ & 44 & 59 & $18 \cdot 2$ & $20 \cdot 5$ & 0 & 0 & 0 \\
\hline Kohn and Srivastava ${ }^{33}$ & 19 & $94 \cdot 7$ & 0 & $5 \cdot 3$ & 0 & 0 & 0 \\
\hline Fine and Lambin ${ }^{34}$ & 68 & 87 & 4 & 9 & 0 & 0 & 0 \\
\hline Kyle et al. ${ }^{35}$ & 15 & $73 \cdot 3$ & $6 \cdot 6$ & 20 & 0 & 0 & 0 \\
\hline Dammacco and Waldenström ${ }^{36}$ & 42 & $80 \cdot 9$ & 19 & 0 & 0 & 0 & 0 \\
\hline
\end{tabular}

and a definite immunological abnormality is such as to suggest a remarkable autoimmune neuropathy.

We are grateful to the consultants of the National Hospitals for Nervous Diseases for allowing us to study their patients and to the staff of the clinical pathology laboratories at the National Hospital, Queen Square.

SNK is supported by the Medical Research Council.

\section{References}

1 Chazot G, Berger B, Carrier H et al. Manifestations neurologiques des gammapathies monoclonales. Rev Neurol 1976;132:195-212.

${ }^{2}$ Hesselvik M. Neuropathological studies on myelomatosis. Acta Neurol Scand 1969;45:95-108.

${ }^{3}$ Logothetis J, Silverstein P, Coe J. Neurologic aspects of Waldenström's macroglobulinemia. Arch Neurol 1960;3:564-73.

${ }^{4}$ McLeod JG, Walsh JC. Neuropathies associated with paraproteinaemias and dysproteinaemia. In: Dyck PJ, Thomas PK, Lambert EH, eds. Peripheral Neuropathy. Philadelphia: WB Saunders, Vol. 2, 1975;1012-29.

${ }^{5}$ Michon P, Larcan A, Streiff F. Neuropathies dysglobulinémiques. Rev Neurol 1959;100:27-40.

${ }^{6}$ Monteverde DA, Morgenfeld MC, Somoza MJ, Bomchil G, Cabrini RL. Manifestations neurologiques de la macroglobulinémie de Waldenström. Rev Neurol 1966;115:1029-49.

${ }^{7}$ Abramson N, Shattil SJ. M-components. J Am Med Ass 1973;223:156-9.

${ }^{8}$ Axelsson U, Bachmann R, Hällén J. Frequency of pathological proteins (M-components) in 6995 sera from an adult population. Acta Med Scand 1966; 179:235-47.

${ }^{9}$ Axelsson U. An 11-year follow-up on 64 subjects with M-components. Acta Med Scand 1977;201:173-5.

${ }^{10}$ Clauvel JP, Danon F, Seligmann M. Immunoglobulines monoclonales décelées en l'absence de myélome ou de macroglobulinémie de Waldenström. Nouv Rev Hematol 1971;11:677-87.

11 Isobe T, Osserman EF. Pathologic conditions associated with plasma cell dyscrasias: a study of 806 cases. Ann NY Acad Sci 1971;190:507-18.

${ }^{12}$ Kohn J. Benign paraproteinaemias. J Clin Path 1974; 28: suppl. 6: 77-82.

${ }^{13}$ Kyle RA. Monoclonal gammopathy of undetermined significance-natural history in 241 cases. $\mathrm{Am} \mathrm{J} \mathrm{Med}$ 1978;64:814-26.

${ }^{14}$ Michaux J-L, Heremans JF. Thirty cases of monoclonal immunoglobulin disorders other than myeloma or macroglobulinemia. Am J Med 1969;46:562-79.

${ }^{15}$ Pick AI, Schoenfeld Y, Skvaril F et al. Asymptomatic (benign) monoclonal gammopathy-a study of 100 patients. Ann Clin Lab Sci 1977;7:335-43.

${ }^{16}$ Ritzmann SE, Loukas D, Sakai H, Daniels JC, Levin WC. Idiopathic (asymptomatic) monoclonal gammopathies. Arch Int Med 1975;135:95-106.

${ }^{17}$ Zawadzki ZA, Edwards GA. Nonmyelomatous monoclonal immunoglobulinemia. Prog Clin Immunol 1972;1:105-56.

${ }^{18}$ Ameis A, Ko HS, Pruzanski W. M-components-a review of 1242 cases. Can Med Ass J 1976;114: 889-95.

19 Colls BM, Lorier MA. Immunocytoma, cancer and other associations of monoclonal gammopathy; a review of 224 cases. NZ Med J 1975;82:221-6.

20 Jensen K, Hom BL, Jensen KB, Olesen H. Characterization of M-components in a large municipal hospital. Dan Med Bull 1969;16:165-70.

${ }^{21}$ Matzke J, Clausen J, Güttler F. The significance of paraproteinaemia in patients with primary neurological symptoms. Acta Neurol Scand 1964:40;269-84.

${ }^{22}$ Peltonen S, Wasastjema $\mathrm{C}$, Wager $\mathrm{O}$. Clinical features of patients with a serum M component. Acta Med Scand 1978;203:257-63.

${ }^{23}$ Stein RS, Ellman L, Bloch KJ. The clinical correlates of IgM M-components; an analysis of 34 patients. Am J Med Sci 1975;269:209-16.

${ }^{24}$ Read DJ, Vanhegan RI, Matthews WB. Peripheral neuropathy and benign IgG paraproteinaemia. $J$ Neurol Neurosurg Psychiat 1978;41:215-9.

${ }^{25}$ Dalakas MC, Engel WK. Chronic peripheral neuropathy with monoclonal immunoglobulin: a clinical and immunohistochemical study of 11 cases (Abstract). Neurology 1979;29:583-4.

${ }^{26} \mathrm{Kohn} \mathrm{J}$. The laboratory investigation of paraproteinaemia. In: Dyke SC, ed. Recent Advances in 
Clinical Pathology, Series 6. London: ChurchillLivingstone, 1973;363-401.

${ }^{27}$ Kohn J, Riches PG. A cellulose acetate immunofixation technique. J Immunol Methods 1978;20:325-31.

${ }^{28}$ Hobbs JR. Paraproteins, benign or malignant? Brit Med J 1967;3:699-704.

${ }^{29}$ Gore ME, Riches PG, Kohn J. Identification of the paraproteins and clinical significance of more than one paraprotein in serum of 56 patients. J Clin Path 1979;32:313-7.

${ }^{30}$ Hobbs JR. Immunocytoma' o'mice an' men. Brit Med $J$ 1971;2:67-72.

${ }^{31}$ Lindstrom FD, Dahlström U. Multiple myeloma or benign monoclonal gammopathy?: a study of differential diagnostic criteria in 44 cases. Clin Immunol Immunopathol 1978;10:168-74.

${ }^{32}$ Sleeper CA, Cawley LP. Detection and diagnosis of monoclonal gammopathy. Am J Clin Path 1969;51: 395-400.

${ }^{33}$ Kohn J, Srivastava PC. Paraproteinaemia in blood donors and the aged: benign and malignant. Protides Biol Fluids 1973;20;257-61.

${ }^{34}$ Fine JM, Lambin P. Distribution of heavy chain classes and light chain types in 757 cases of monoclonal gammapathies. Biomedicine (Express) 1975; 23:323-7.
${ }^{35}$ Kyle RA, Finkelstein S, Elveback LR, Kurland LT. Incidence of monoclonal proteins in a Minnesota community with a cluster of multiple myeloma. Blood 1972;40:719-24.

${ }^{36}$ Dammacco F, Waldenström J. Bence-Jones proteinuria in benign monoclonal gammapathies. Acta Med Scand $1968 ; 184 ; 403-9$.

${ }^{37}$ Massey EW, Pleet AB, Brannon WL. Waldenström's macroglobulinemia and mononeuritis multiplex. Ann Int Med 1978;88:360-1.

${ }^{38}$ Swash M, Perrin J, Schwartz MS. Significance of immunoglobulin deposition in peripheral nerve in neuropathies associated with paraproteinaemia. J Neurol Neurosurg Psychiat 1979;42:179-83.

${ }^{39}$ Nusselt L, Rieder HP, Kaeser HE. Serumproteinveränderungen bei Polyneuritis. Schweiz Med Wschr 1971;101:1479-82.

${ }^{40}$ Link H. Comparison of electrophoresis on agar gel and agarose gel in the evaluation of gamma-globulin abnormalities in cerebrospinal fluid and serum in multiple sclerosis. Clin Chim Acta 1973;46:383-9.

Requests for reprints to: Dr Sidney N Kahn, Neurochemistry Department, Institute of Neurology, Queen Square, London WCIN 3BG, UK. 